\title{
UERGS: RASTROS DE UMA ARTE MICROPOLÍTICA DE (RE)EXISTÊNCIA
}

\section{UERGS: TRACES OF A MICROPOLITICAL ART OF (RE)EXISTENCE}

\author{
Jaqueline Madruga Flesch ${ }^{1}$ \\ Dulce Mari da Silva Voss ${ }^{2}$
}

\section{RESUMO}

Essa escrita traça rastros da arte de (re)existência da Universidade Estadual do Rio Grande do Sul (UERGS) ativada pelo compromisso ético-estético-político de defesa da educação pública e de qualidade social na campanha gaúcha. Por meio de um estudo de caso e da análise documental de dispositivos legais, institucionais e produção bibliográfica, guiada pela perspectiva pós-estruturalista, evidencia-se contingências macropolíticas em que forças neoliberais provocam a precarização do trabalho docente e impõem uma sobrevida às instituições públicas de educação superior em nosso país e região. Ao passo que, movimentos micropolíticos de uma maquinaria de guerra, posta em funcionamento no ensino, pesquisa e extensão, agem na contramão dessa ordem. É assim que a UERGS tem protagonizado a criação de sua paisagem existencial em aliança com movimentos sociais, instituições e sujeitos. Composição de forças e potências que possibilitam a reapropriação coletiva da pulsão vital.

Palavras-chave: Educação Pública; Neoliberalismo; Resistência.

\section{ABSTRACT}

This writing traces the art of (re)existence of the State University of Rio Grande do Sul (UERGS), activated by an ethical-aesthetic-political commitment to defend public education and social quality in the Campanha Gaúcha region. Through a case study and analysis of legal, institutional and bibliographic production, guided by the post-structuralist perspective, this research revealed macropolitical contingencies in which neoliberal forces cause the precariousness of teaching and impose a survival mode on public institutions of higher education in our country and region. However, war-like micro-political movements are acting against this order in teaching, research, and extension. This is how UERGS has led the creation of its existential landscape in alliance with other social movements, institutions, and subjects. Composition of forces and powers that enable the collective reappropriation of the vital drive.

Keywords: Public education; Neoliberalism; Resistance.

\footnotetext{
${ }^{1}$ Especialista em Docência para o Ensino Superior. Licenciada em Sociologia pela Universidade Paulista (UNIP). Atualmente é graduanda em Pedagogia pela Universidade Estadual do Rio Grande do Sul (UERGS). e-mail: fleschjaqueline@gmail.com

2 Atualmente é Professora Associada da Universidade Federal do Pampa (UNIPAMPA/Campus Bagé - RS). Doutora e Mestra em Educação pela Universidade Federal de Pelotas. e-mail: dulcevoss@ unipampa.edu.br
} 


\section{novistet

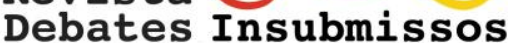

\section{INTRODUÇÃO}

Essa escrita visa potencializar o pensamento e a ação política em defesa da educação pública e do direito à vida. Ao escrever, assumimos o risco de dizer o que pensamos, do modo como pensamos, de estar no mundo e desejar nele intervir. Já dizia Foucault (1996, p. 08-10): "O discurso não é simplesmente aquilo que manifesta (ou oculta) o desejo; é, também, aquilo que é o objeto do desejo. O discurso não é simplesmente aquilo que traduz as lutas ou sistemas de dominação, mas aquilo por que, pelo que se luta".

Traçados escritos em desvio à tradição moderna que institui certas verdades acerca do mundo e da vida aprisionada numa sucessão linear de fatos passados e presentes, cuja interpretação levaria, necessariamente, à pretensa evolução rumo a um "futuro melhor". Sob a perspectiva pós-estruturalista, lançamo-nos numa mirada que subverte tal lógica. Concebemos o presente como produção de forças macro e micropolíticas que afetam existências, o que requer a tomada de posição diante das contingências históricas de colonização da vida e do desejo:

Luta que requer multiplicar vozes dissonantes e insurgências no mundo colonial capitalístico contemporâneo para escapar aos agenciamentos do cientificismo moderno que solidificam o pensamento em torno de sociedades, coletividades, individualidades, subjetividades, tempos e espaços políticos, sociais, culturais. Criar, dentro e fora desses estratos, forças e fluxos como outras linhas e formas de pensar (re)existências, outros mundos possíveis nesse mundo presente, é o desafio em construção (VOSS, IN: ROCHA; MAGALHÃES; OLIVEIRA, 2020, p. 222).

Operamos o pensamento como maquinaria de guerra $^{3}$ que fabrica multiplicidades, subvertendo a lógica moderna arbórea, criando um estilo rizomático ${ }^{4}$, movediço, intermezzo, nômade, sem fixar sentidos. Pensamento em que:

Pensar é, primeiramente, ver e falar, mas com a condição de que o olho não permaneça
nas coisas e se eleve até as visibilidades, e de que a linguagem não fique nas palavras
ou frases e se eleve até os enunciados. É o pensamento como arquivo. Além disso,
pensar é poder, isto é, estender relações de força, com a condição de compreender que
as relações de força não se reduzem a violência, mas constituem ações sobre as ações,
ou seja tais como "incitar, induzir, desviar, facilitar ou dificultar, ampliar ou limitar,

\footnotetext{
${ }^{3} \mathrm{O}$ conceito de máquina de guerra criado por Deleuze e Guattari (2012), inspirado no modo de existência nômade, tem a ver com a potência do movimento, deslocamento de forças, agenciamentos que podem provocar e instaurar novas formas de existência.

${ }^{4}$ Deleuze e Guattari (2011), criam o conceito rizoma como princípio de multiplicidades; o rizoma pode ser rompido, quebrado em um lugar qualquer, formando linhas de fuga, pelas quais novas atribuições se criam, e também pode ser retomado, reterritorializado em outras linhas.
} 


\section{Revista \\ Debates Insubmissos}

tornar mais ou menos provável...”. É o pensamento como estratégia. Trata-se da constituição de modos de existência ou, como dizia Nietzsche, a invenção de novas possibilidades de vida (DELEUZE, 1992, p. 119-120).

Desse modo, inventamos rastros de uma arte de (re)existência da paisagem existencial da Universidade Estadual do Rio Grande do Sul (UERGS) que, em aliança com múltiplas forças, assume o compromisso ético-estético-político de protagonizar o direito à educação pública e de qualidade social na campanha gaúcha. Movimentos micropolíticos do pensar, criar e agir na contramão à ordem macropolítica ditada pelos interesses do capital finaceirizado e os duros golpes que forças neoliberais ${ }^{5}$ têm lançado contra instituições públicas de educação superior, categorias profissionais e grupos sociais subalternos, no que tange ao enxugamento e contenção de recursos públicos, e que favorece a expansão da privatização do ensino e da pesquisa, expondo as universidades brasileiras às garras de um mercado educacional em crescimento vertiginoso.

Desmonte do direito à educação pública e de qualidade social que aprofunda desigualdades, borra o cenário das lutas sociais e suspende conquistas alcançadas por trabalhadores/as e outras coletividades, nas décadas de 1980 e 1990. Disputas também travadas no campo educacional que, no início dos anos 2000, forçaram o estado liberal a expandir a oferta da educação superior pública e a incorporar demandas sociais nos currículos dos cursos.

Vivemos um presente de ameaças e golpes neoliberais que, em nome de enxugar “despesas”, vulnerabilizam instituições públicas, forçam a adoção de parcerias com o capital privado para a manutenção do ensino, da extensão e da pesquisa, reduzem o contingente de profissionais da educação, atraem educadores/as pelo neotecnicismo, impõem condições indignas de existência mediante a quebra dos planos de carreira, sobrecarga de trabalho e incremento da vigilância, controle e perseguição à todas as forças de oposição ao regime capitalístico colonial. Daí a urgência em intensificar alianças na resistência às macropolíticas

\footnotetext{
5 O neoliberalismo fundamenta-se no modelo empresarial cujos princípios básicos são: concorrência, produtividade e empreendedorismo para expansão do capitalismo em todas as esferas da vida social: "trata-se da individualização da política social, ou seja, não se trata de assegurar aos indivíduos uma cobertura social dos riscos, mas de conceder a cada um uma espécie de espaço econômico dentro do qual podem assumir e enfrentar os riscos" (FOUCAULT, 2008, p. 198).
} 
neoliberais e neoconservadoras ${ }^{6}$ em múltiplos espaços, incluindo as universidades, no sentido de criar possibilidades outras, pois o que está em jogo é o acesso ao trabalho, à saúde, à educação, à habitação, em suma, o direito de existir singularmente.

Partindo desta breve contextualização, propomos aqui dois movimentos do pensamento: uma problematização em torno das lutas contra a tomada de poder pelo capitalismo financeirizado que se alastra pelo mundo, no qual o desmonte neoliberal e neoconservador dos direitos sociais tem sido intensificado cada vez mais, o que compromete a garantia da educação superior pública, seguido da análise feita na pesquisa que nos leva a perceber estratégias de (re)existência protagonizadas pela UERGS, ao enfrentar enormes adversidades e não sucumbir aos ataques de sucessivos (des)governos estaduais e nacionais.

Num contexto de infraestrutura precária, um contingente de docentes e técnicos reduzido, falta de recursos para a pesquisa, entre outras dificuldades que têm assolado a vida desta instituição pública, a paisagem existencial da Universidade Estadual do Rio Grande do Sul (UERGS) não nos parece capturada, mas remete a criação de uma micropolítica de (re)existência na qual teima em lutar em defesa da educação pública e de qualidade social, em ações inventivas e singulares.

\section{O EMBATE DE FORÇAS NA EXPROPRIAÇÃO/APROPRIAÇÃO DA VIDA}

No texto "Esferas da Insurreição: Notas para uma vida não cafetinada", Suely Rolnik (2018) escreve sobre "a tomada planetária do poder pelo capitalismo financeirizado e neoliberal", cujas origens encontram-se no final do século XV, com a tomada das colônias americanas, asiáticas e africanas pelos colonizadores europeus, e que se solidificou desde o final da Primeira Guerra Mundial, a partir dos séculos XIX e XX, ao alastrar-se pelo mundo via internacionalização dos capitais. Globalização capitalista que gerou forças reativas, encarnadas pelos movimentos sociais dos anos de 1960 e 70, bem como, forjou, desde meados dos anos

\footnotetext{
${ }^{6}$ Ao neoliberalismo alia-se o neoconservadorismo que, em linhas gerais, pode ser definido como exaltação ao passado, uma tentativa de voltar aos costumes tradicionais, ideal moralista, patriótico e fundamentalista que combate culturas, povos, sujeitos e movimentos dissidentes do padrão colonial eurocêntrico.
} 
90, a criação de "um novo tipo de ativismo" iniciado pelas lutas feministas, de negros/as, LGBTQI+ em ações macro e micropolíticas de defesa, não apenas da igualdade de direitos sociais, mas de tamanha insurgência em favor do direito que engloba todos os demais: "o direito de existir".

A autora refere-se a vida como potência criadora e à luta contra a expropriação da pulsão vital (desejo), uma vez que o "regime colonial capitalístico (cafetinagem)" age para capturar e submeter subjetividades aos seus preceitos e tecnologias nefastas, à medida que regimenta uma legião de "zumbis" pelo mundo afora: "Períodos de convulsão são sempre os mais difíceis de viver, mas é neles também que a vida grita mais alto e desperta aqueles que ainda não sucumbiram integralmente à condição de zumbis - uma condição a que estamos todos destinados pela cafetinagem da pulsão vital” (ROLNIK, 2018, p. 25).

O combate à expropriação da pulsão vital requer a luta e a resistência tanto no campo macropolítico de enfrentamento às ações do capital e dos estados contra os direitos sociais, quanto reivindica um esforço coletivo e individual de práticas ativistas, artísticas, humanas, de reapropriação do impulso de criação, ou seja, ações que dirigem o desejo na produção da subjetividade e nos modos como nos relacionamos uns com os outros. Algo que não depende de uma simples vontade pessoal, supostamente natural, ou coletiva, movida por uma consciência lúcida e bem-intencionada. Mas, trata-se da conquista e construção de um território comum, viabilizado pela cooperação em conexões temporárias de forças que interligam comunidades numa forma sinérgica que ativa a produção da política, do pensamento e da cultura, multiplica potências, gera ressonâncias capazes de desarmar o poder cafetinado. Como dito por Rolnik:

Tais ressonâncias e as sinergias que produzem criam as condições para a formação de um corpo coletivo comum cuja potência de invenção agindo em direções singulares e variáveis, possam refrear o poder das forças que prevalecem em outras constelações aquelas que se compõem de corpos que tentam cafetinar a pulsão vital alheia ou que se entregam a sua cafetinagem. Com essas sinergias, abrem-se caminhos para desviar tal potência de seu destino destruidor (ROLNIK, 2018, p. 39).

Não estamos propondo a ideia de uma composição de forças coesas e permanentemente unidas ou unânimes em ação contra às macropolíticas neoliberais e neoconservadoras. Não pensamos existir blocos de forças que sejam unidades perfeitas, Até 
porque nada nem ninguém está isento da sedução que tais políticas exercem sobre o desejo de muitos grupos e indivíduos que se deixam levar por um "espírito empreendedor e meritocrático", impregnado nas instituições na contemporaneidade.

Além disso, não podemos esquecer que, assim como outras instituições que emergem no mundo ocidental moderno, as universidades brasileiras são herdeiras de uma cultura eurocêntrica e do modelo antropocêntrico que define o humano como entidade e razão universal, baseado no conhecimento científico e no pensamento cartesiano. Racionalidade cartesiana e geopolítica moderna que sustenta regimes de verdade e relações de poder-saber acerca do que é a cultura, o tempo, o espaço, o humano, a civilização, o progresso, e se impõe como padrão de produção da existência na vida social capturada pelo mercado capitalista. Contudo, também é no interior destas estruturas e estratos condensados que, em tempos passados e presentes, outros discursos e práticas se movem, muitas lutas foram e continuam sendo travadas: "Um vir a ser que intensifica o giro ontológico e epistemológico e as estratégias de luta no combate contra a colonialidade do poder, do ser e do saber" (VOSS, In: ROCHA; MAGALHÃES; OLIVEIRA, 2020, p. 237).

É com base no estudo de caso que deu vazão a essa escrita que percebemos a emergência da criação de macro e micropolíticas de resistência à cafetinagem neoliberal e neoconservadora, haja visto a mobilização e articulação em conexões temporárias e múltiplas de coletivos que, em seus espaços de atuação cotidiana, nas relações sociais e de trabalho, enfrentam de modo criativo os duros golpes dos (des)governos neoliberais e setores neoconservadores.

\subsection{O ataque à educação pública}

Nas décadas de 1960 a 80, as universidades públicas brasileiras foram espaços de efervescente debate, produção de conhecimento e movimentação política, constituindo, com outras forças, movimentos de resistência ao regime militar e que garantiram conquistas importantes quanto aos direitos civis e sociais.

Já na década de 1990, o estado brasileiro, como que em resposta à crescente movimentação social, aderiu às políticas neoliberais mundiais que induziram à redução do 


\section{Revista \\ Debates Insubmissos}

Estado de Bem-Estar Social, favorecendo o lucro do mercado interno e externo via privatização das instituições, dos serviços e do patrimônio público. Neste cenário aconteceu a promulgação da Lei de Diretrizes e Bases da Educação Nacional (LDBEN), Lei Federal nº 9.394/96, que, entre outras reformas, redimensionou as instituições de educação superior, alterando a estrutura e a organização dos cursos de graduação. Além das universidades, novas configurações institucionais foram criadas, como os centros universitários, as faculdades integradas e os Institutos Superiores de Educação (ISE).

Logo, a incorporação da educação pública estatal nas agendas das reformas globais tem sido pautada, desde então, pela definição de políticas de oferta, avaliação, financiamento, formação de professores e currículos organizados e regulados por mecanismos de mercado, como a competitividade, a produtividade e o controle de resultados. Também, a capacitação em serviço e em cursos não presenciais, ofertados na modalidade de Educação à Distância $(\mathrm{EaD})$, tem crescido sobremaneira (VOSS, 2021).

Essa política de flexibilização via diversificação na organização institucional e 100 acadêmica serviu como estratégia política para a expansão da oferta da Educação Superior e elevação do nível de escolaridade nos países que buscam enquadrarem-se na agenda das reformas neoliberais proposta pelas organizações multilaterais, como o Banco Mundial que indica a elevação do nível de escolarização da população dos países periféricos mediante o enxugamento dos recursos públicos e a implantação de parcerias com a iniciativa privada (VOSS, 2021).

Com base em Freitas (1999), indicamos algumas reformas neoliberais que afetam a formação acadêmica, especialmente nos cursos de formação docente, como: neotecnicismo; ênfase na prática profissional em detrimento da formação acadêmica (como exemplo podemos citar a implantação de cursos de pós-graduação profissionais); individualismo e responsabilidade pessoal no processo formativo; avaliação do desempenho estudantil, docente e institucional que conduz e reforça a meritocracia;, discurso empresarial da competência, empreendedorismo e eficiência que foi incorporado nas diretrizes pedagógicas e nos currículos dos cursos de graduação e pós-graduação. 


\section{Revista \\ Debates Insubmissos}

No ano de 2014, um novo Plano Nacional de Educação é instituído com a promulgação da Lei 13.005/2014, sem a participação efetiva das entidades e movimentos sociais, incrementando ainda mais a tomada da educação pelo neoliberalismo. Ao contrário do que a sociedade civil organizada tinha pleiteado desde a proposta do PNE da Sociedade Brasileira, o governo federal adiou no PNE a ampliação dos $10 \%$ do Produto Interno Bruto (PIB) a ser investido na educação para o fim do decênio, indicando explicitamente a continuidade e o acirramento das políticas de privatização da educação.

Com isso, o PNE reforçou a política de sucateamento e precarização do trabalho na educação superior pública pela via empresarial de cobrança dos resultados, como previsto na meta 12 que prescreve a elevação da taxa conclusão média dos cursos de graduação presenciais nas universidades públicas para $90 \%$ e a relação do número de estudantes por professor para 18, ao passo que, na meta 13 , o percentual de conclusão da graduação nas universidades privadas é fixado em $75 \%$. Ou seja, a cobrança pela melhoria dos resultados torna-se maior sobre as universidades públicas que passam a receber menos recursos orçamentários.

O PNE anuncia a expansão dos investimentos públicos na educação superior privada, pois, também na meta 12, está previsto a ampliação do Fundo de Financiamento ao Estudante ao Ensino Superior (FIES) e do Programa Universidade para Todos (PROUNI), os quais garantem o pagamento de bolsas com recursos públicos aos estudantes das universidades privadas. Ainda, na meta 17, a equiparação salarial dos profissionais do magistério com outros profissionais que possuem escolaridade equivalente, que foi uma das reivindicações das entidades que participaram da Conferência Nacional de Educação de 2014, no texto da lei foi negada.

Para fazer valer uma política de expansão da oferta a qualquer custo, o PNE recorre ao discurso da interiorização das universidades, da abertura de novos cursos profissionalizantes (tecnólogos) e educação à distância. Na meta 12 está posto: “[...] otimizar a capacidade instalada da estrutura física e de recursos humanos das instituições públicas de educação superior, mediante ações planejadas e coordenadas, de forma a ampliar e interiorizar o acesso à graduação". O termo "otimizar" indica que a expansão da oferta deve ser alcançada sem a 


\section{Revista \\ Debates Insubmissos}

ampliação dos recursos físicos, orçamentários e humanos, o que já acontece no estado do RS e na região da campanha gaúcha, onde a UERGS está localizada, pois em termos de infraestrutura as condições são precárias e o quadro de docentes e técnicos administrativos é bastante limitado. Ou seja, vale a premissa empresarial "é preciso fazer mais com menos".

Embora as universidades localizadas nas áreas centrais do país também sejam atingidas pelos cortes orçamentários, em regiões periféricas e interioranas as instituições de educação superior tendem a concentrar seus parcos recursos no ensino e, por vezes, na extensão, em detrimento das atividades de pesquisa em razão das condições desfavoráveis. Com isso, há uma quebra do princípio da indissociabilidade de ensino, pesquisa e extensão que historicamente constitui a identidade das universidades públicas.

Assim, para muitas instituições públicas de educação superior brasileiras existir tem sido um exercício diário de resistência, de luta inventiva para encontrar e multiplicar forças em defesa da legitimidade do seu trabalho científico e do compromisso social assumido nas comunidades e localidades em que estão inseridas de modo a garantir seu caráter e atuação pública. Evidenciar esta luta na qual manifestamos engajamento científico e político, foi o que moveu o desejo de realizar a pesquisa descrita a seguir.

\section{METODOLOGIA}

Por meio de um estudo de caso de abordagem qualitativa do contexto pesquisado e das ações empreendidas pela Universidade Estadual do Rio Grande do Sul (UERGS) em âmbito local, procuramos evidenciar a produção de uma micropolítica de resistência ao desmonte da educação pública. Para isso, recorremos aos documentos oficiais, como o regimento da universidade, e informações extraídas do site da UERGS, além de produções bibliográficas de docentes e estudantes desta instituição de educação superior.

De acordo com Bogdan e Biklen (1994), o estudo de caso de abordagem qualitativa caracteriza-se como uma investigação na qual a fonte direta de dados possibilita examinar detalhadamente a configuração de um contexto particular, em que nada é trivial, tudo o que constitui essa unidade pode servir como pista para estabelecer uma compreensão mais 
esclarecedora do objeto estudado. O processo de busca e de organização sistemática dos materiais obtidos em unidades manipuláveis, a procura de padrões, possibilita a descoberta dos aspectos importantes e do que deve ser apreendido e produzido na análise dos dados.

Esses movimentos investigativos junto ao direcionamento do olhar às minúcias, possibilitado pelo estudo de caso, viabilizam desbravar e destacar multiplicidades e singularidades que compõem o objeto de pesquisa e seus elementos. Ao tomarmos o pósestruturalismo como perspectiva epistemológica e filosófica, mobilizamos o pensar como máquina de guerra na intencionalidade de fabricar multiplicidades, assumindo um compromisso com a diferença enquanto categoria central do pensamento. Assim, a pesquisa não pode se dar através de caminhos fixos, os métodos e trajetos metodológicos se constroem no próprio ato de pesquisar.

Opondo-se às concepções modernas, “[...] a perspectiva pós-estruturalista entende que não se pode estabelecer de antemão o processo de pesquisa, pois nada assegura que o planejado a priori se concretize ou que postulações teóricas previamente estabelecidas funcionem" (TEDESCHI; PAVAN, 2017, p. 2). Pensando no desenvolvimento de pesquisas em educação, ao descentralizar as metanarrativas da racionalidade moderna ocidental, afastando-nos da rigidez de caminhos pré-definidos e dos pressupostos de universalidade, identidade etc., conseguimos potencializar nossos estudos e abrir espaço para significar e ressignificar ações e processos educativos.

A questão colocada pelo pós-estruturalismo é a não limitação da pesquisa a procedimentos e práticas arranjadas previamente. A ideia é buscar caminhos outros para pesquisar, onde haja múltiplas possibilidades metodológicas que ultrapassem perspectivas iniciais. Assim, "podemos sair do aprisionamento, da fixidez, do essencialismo metodológico" e "encontrar novos modos de fazer pesquisa em educação". Dessa forma, a pesquisa pode adentrar caminhos ainda pouco explorados e "resistir a práticas e saberes que se colocam como permanentes, a sentidos que se apresentam como fixos, a tempos e espaços que parecem lineares demais" (TEDESCHI; PAVAN, 2017, p. 13). 
Os movimentos que nós propomos aqui vão ao encontro dessa busca por caminhos outros no pesquisar e no existir, pois buscamos evidenciar micropolíticas de resistência que se movimentam em contracorrente às políticas neoliberais e neoconservadoras e ataques dos (des)governos estaduais e nacionais. À vista disso, a Universidade Estadual do Rio Grande do Sul ganha destaque como instituição corajosa que enfrenta o sucateamento da educação superior criando no Município de Bagé um solo fértil de reapropriação coletiva de potência e força vital (ROLNIK, 2018).

\section{A UERGS QUE (RE)EXISTE}

A Universidade Estadual do Rio Grande do Sul (UERGS) foi criada em 2001 mediante a Lei $\mathrm{n}^{\mathrm{o}} 11.646$, de 10 de julho. Conforme o documento, a Instituição se organiza como Fundação Multicampi, possuindo Campi Regionais, Unidades Universitárias e Unidades Complementares, tendo sede e foro em Porto Alegre, capital do Estado. De acordo com o Art. $1^{\mathrm{o}}$ têm gratuidade nos cursos regulares, possuindo "autonomia pedagógica, didática, científica, administrativa e de gestão financeira e patrimonial” (RIO GRANDE DO SUL, 2001, p. 1).

Quanto às Unidades Universitárias, os documentos da UERGS preveem a organização de Institutos, Faculdades e Centros de Ensino e Pesquisa, o que indica a adequação às reformas da educação superior que flexibilizam e fragilizam as condições de articulação entre ensino, pesquisa e extensão que historicamente caracterizaram as instituições pela indissociabilidade dessas áreas. 


\section{Revista \\ Debates Insubmissos}

Figura 1: Mapa das Unidades Universitárias que compõem a UERGS
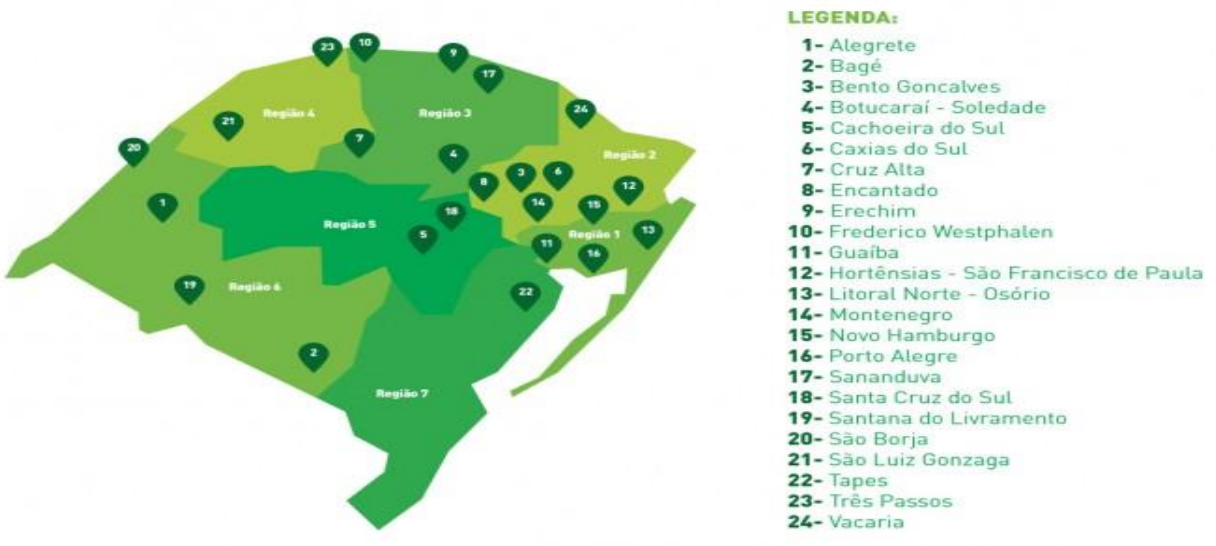

Fonte: site da UERGS

Como órgãos deliberativos, a Instituição possui o Conselho Superior da Universidade (CONSUN) e o Conselho de Ensino, Pesquisa e Extensão (CONEPE). A Reitoria, as Unidades

Universitárias e as Unidades Complementares compõem os órgãos executivos. Para fiscalização, a Universidade tem o Conselho Curador. (RIO GRANDE DO SUL, 2004). Regendo a Instituição, há a Lei de criação, o Estatuto lançado em 2004, o Regimento Geral e as das Resoluções do CONSUN e da Reitoria.

De acordo com o Estatuto e Lei de criação, a Universidade Estadual do Rio Grande do Sul objetiva o desenvolvimento regional sustentável, algo que pode ser interpretado como "educar para desenvolver", o que está diretamente relacionado ao capitalismo e seu compromisso com a produção econômica. Além disso, a Instituição prevê a garantia do ensino de graduação, pós-graduação e tecnólogos, a promoção de extensão, o desenvolvimento de pesquisa e a assessoria tecnológica e científica. Os documentos falam em formação humanística e inovação, considerando as letras, as artes e as tecnologias, mas não explicam como isso deve funcionar.

Como órgãos deliberativos, a Instituição possui o Conselho Superior da Universidade (CONSUN) e o Conselho de Ensino, Pesquisa e Extensão (CONEPE). A Reitoria, as Unidades 


\section{Revista \\ Debates Insubmissos}

Universitárias e as Unidades Complementares compõem os órgãos executivos. Para fiscalização, a Universidade tem o Conselho Curador. (RIO GRANDE DO SUL, 2004). Regendo a Instituição, há a Lei de criação, o Estatuto lançado em 2004, o Regimento Geral e as das Resoluções do CONSUN e da Reitoria.

A seleção de alunos aos cursos regulares ocorre através de seleção pública que considera a condição socioeconômica dos candidatos e assegura 50\% das vagas a estudantes com menor renda familiar (hipossuficientes). Considerando isso, os documentos preveem programas que auxiliem nas despesas de alunos com baixo poder aquisitivo. Há ainda reserva de vagas a estudantes negros e indígenas cuja proporção mínima depende dos dados do IBGE referentes ao contingente populacional dessas etnias no Estado. Ademais, a Instituição dispõe reserva de ao menos $10 \%$ para candidatos portadores de deficiência.

Essa normativa indica a incorporação de demandas sociais que lutam pela garantia do acesso à educação superior pública. Cabe, no entanto, entender que o acesso não se limita ao ingresso. Para que os estudantes possam permanecer e concluir com êxito sua formação há de garantir recursos públicos mais efetivos e, para isso, o investimento estatal é imprescindível, o que não tem acontecido com as políticas neoliberais. Os programas para auxílio às despesas de alunos com baixo poder aquisitivo vem perdendo número de bolsas, atendendo cada vez menos estudantes.

Os (des)governos estaduais e federais brasileiros têm se utilizado de discursos que descredibilizam o trabalho docente nas instituições públicas de ensino superior. Esses movimentos discursivos se manifestam como tentativas de legitimar os golpes que as Universidades vêm sofrendo e os cortes orçamentários que prejudicam as condições de oferta e manutenção da qualidade da educação superior no país.

À vista disso, podemos pensar nas discussões trazidas por Foucault (2014) referentes às operações feitas na ordem do verdadeiro para o governamento e condução de indivíduos, estados ou populações. No Brasil esses discursos têm funcionado como mecanismos para invalidar o trabalho docente e legitimar o enxugamento de "despesas" e a premissa empresarial, mencionada anteriormente, que afirma ser preciso "fazer mais com menos". Considerando esse 


\section{Revista \\ Debates Insubmissos}

cenário, daremos destaque aos dados referentes à UERGS Bagé por ser uma unidade que dentro da própria Universidade trava batalhas para existir e resistir aos ataques à educação pública de qualidade social.

\subsection{Paisagem existencial da Unidade Bagé}

A Unidade Universitária da UERGS Bagé foi fundada no ano de 2002, tornando-se a primeira instituição pública a ofertar cursos de graduação e tecnólogos na região, cenário fronteiriço (Brasil/Uruguai) de predomínio da cultura agropastoril e de escassez de políticas públicas voltadas às populações de menor renda e de oferta de educação superior limitada à iniciativa privada. Anos depois, é fundada a Universidade Federal do Pampa (2008) e o Instituto Federal Sul-Riograndense (2010).

Em tempos passados, a Unidade ofertou dois cursos tecnólogos, em Fruticultura e Silvicultura. Esses cursos seguiram a premissa do "desenvolvimento regional sustentável", pois tinham como objetivo o crescimento econômico da região da Campanha, considerando a base econômica da produção local, o que reforça a lógica da educação superior de formação profissional voltada aos interesses capitalistas.

Todavia, a UERGS vem se constituindo e fortalecendo seu compromisso com a educação pública de qualidade mesmo frente às condições desfavoráveis. Uma dessas condições que vem acompanhando a Universidade e, em destaque, a de Unidade Bagé, é o contingente restrito de professores, conforme é evidenciado na tabela a seguir: 
Tabela 1: Contingente de docentes da Unidade de Bagé e suas respectivas formações

\begin{tabular}{lll}
\hline Docentes & Formação Inicial & Formação Atual \\
\hline A & Psicologia & Mestrado com Doutorado em andamento \\
\hline B & Educação Física & Mestrado com Doutorado em andamento \\
\hline C & Pedagogia & Doutorado \\
\hline D & Educação Física & Especialização com Mestrado em andamento \\
E & Graduação em Letras & Mestrado com Doutorado em andamento \\
\hline F & Graduação em Letras & Doutorado \\
\hline G & Pedagogia & Doutorado \\
\hline
\end{tabular}

Fonte: Site da UERGS e Plataforma Lattes

De acordo com os dados, o contingente de docentes da Unidade de Bagé se restringe a apenas sete professoras. À vista disso, nos últimos anos tem contado com professores/as convidados/as, pois o Estado do Rio Grande do Sul não autoriza a abertura de concurso público há sete anos. Enxugamento e precarização das condições de exercício da docência que leva a necessidade de recorrer a professores/as de fora, das outras Unidades e visitantes, o que pode fragilizar as relações entre docentes e estudantes e a comunidade local, uma vez que as atividades de professores externos são pontuais para atendimento de demandas muito específicas e temporárias. A sobrecarga de trabalho do corpo docente do quadro de efetivos é evidente. Precisam dar conta das atividades de organização curricular e gestão dos cursos, além das atividades de ensino (oferta de disciplinas regulares, orientação de estágios, trabalhos de conclusão de curso de graduação e pós-graduação, coordenação de Programas como: Residência Pedagógica e Iniciação à Docência - PIBID).

O fato de a Unidade não ter um quadro maior de professores/as efetivos dificulta a abertura de novos cursos de graduação. Atualmente, há apenas a Graduação em Pedagogia (Licenciatura) e cursos de Especialização na área da Educação. Conforme o site da Universidade, o Licenciado em Pedagogia pela UERGS deve se posicionar sobre questões do 
cotidiano educacional e referentes à sociedade, atuando sobre o seu campo, inserindo-se na educação formal ou informal, tendo solidariedade, criatividade e disponibilidade para um novo fazer educativo ante diferenças etárias e culturais. O perfil do egresso também inclui capacitação em fazer leituras críticas da realidade, buscando alternativas, articulando saberes, aprendendo e transformando a educação.

Corroborando com isso, Camozzato (2015), uma das professoras efetivas da Unidade de Bagé, escreve que é no cotidiano que o professor se torna tal sujeito. A autora ressalta a pesquisa e o estudo na procura de formas inventivas de agir, inventando novas perguntas e criando novas respostas provisórias. Em sua escrita, enfatiza a necessidade dos docentes assumirem o papel de diagnosticar o tempo presente e atuar na realidade mediante análise, diagnóstico, interpretação etc. do tempo e espaço em que estão inseridos. Sobre isso, destaca:

[...] a urgência de pensarmos que a condição da professoralidade não está desalojada do contexto espaço-temporal que o circunda e produz. Somos, sobretudo, sujeitos históricos e exatamente, por isso reconhecermos a função de diagnosticadores do tempo presente nos incute a responsabilidade de andarmos inquietos, com a problematização e a procura por fazermos escolhas éticas e estéticas, que produzam singularidades. Discutir as condições de exercer a docência nos tempos atuais e o quanto o fazer docente envolve uma análise sobre os momentos de voltar para si de modo a problematizar a própria condição e constituição desse fazer parece ser uma das tantas urgências que nos acomete. (CAMOZZATO, 2015, p. 77-78).

Através do curso de Pedagogia e das Especializações na área da Educação, oferecidas desde 2015, diferentes áreas do conhecimento vêm sendo articuladas para incremento da formação docente: Gestão de Currículo na Formação Docente; Docência no Ensino Religioso; Gestão em Educação: Supervisão e Orientação; Educação Infantil: Currículo e Metodologias para a criação de propostas Inovadoras; e Temas Contemporâneos na Educação: Cidadania e Mobilidade. A oferta destes cursos se sustenta graças a parcerias entre a Unidade, professores/as convidados/as de outras instituições, como o Departamento Estadual de Trânsito (DETRAN/RS). Esse movimento se dá como forma de resistir ao (des)governo do Estado do RS que, não só não investe no aumento do contingente de professores da Universidade há anos, mas também corta recursos orçamentários.

Outra forma de enfrentar as condições precárias é construir alternativas que somem forças coletivas no intuito de garantir a indissociabilidade ensino, pesquisa e extensão, surge 
com os projetos de pesquisa em andamento: "Letramento, Letramento Literário e Letramento Digital nas Escolas de Bagé”, que conta com a participação de professores da Universidade Federal do Pampa (UNIPAMPA), Universidade do Minho e Universidade Estadual de Campinas (UNICAMP). Esse projeto é encampado pelo Grupo de Pesquisa e Estudos Integrados à Educação: linguagens e letramentos (GPEIE) liderado por uma das professoras adjuntas da Unidade. Também se destaca a ação efetiva do Grupo de Pesquisa Educação, Culturas e Pedagogias (DESLOGOGIAS), liderado por outra professora da Unidade Bagé e aliado a Universidade Federal do Rio Grande do Sul (UFRGS), a Universidade Federal de Rio Grande (FURG), Instituto Federal de Santa Catarina (IFSC) e outras instituições de educação superior do país e também de Portugal.

Levando em conta a formação continuada de professores, a Unidade Bagé abriu espaço para discussão de Literatura e Educação. A ação se deu através de Mateada Literária e possuiu palestrantes e oficineiros de diversas Instituições, tais como a Universidade Federal do Pampa (UNIPAMPA), a Universidade Estadual de Campinas (UNICAMP) e Instituto Federal do Rio Grande do Sul (IFSUL). Algumas oficinas contaram com pós-graduandos de Teoria e História Literária da Unicamp que abordaram a literatura relacionando-a às artes visuais, ao ensino de língua estrangeira, à crítica literária, à infância, dentre outras temáticas. A iniciativa teve como premissa a transversalidade da formação humanista do docente que perpassa o literário. Além dessas propostas, o evento também dispôs de sarau promovido pelo Movimento dos Escritores Bageenses (MEB).

A UERGS Bagé também é presente nas Feiras do Livro organizadas pelo Serviço Social do Comércio (SESC) e a prefeitura do Município. Só na 22 ${ }^{\text {a }}$ Edição do evento, realizada em 2019, a Unidade promoveu oito ações diferentes, que abarcaram oficinas, teatros, exposições, contações de história e rodas de conversa. As propostas contaram com público de diversas idades e se ampararam na temática "Literatura: herança e saberes dos povos" que orientou a Feira naquele ano. $\mathrm{O}$ evento é culturalmente importante para a região e oferece entrada franca, também possibilitando visitações com turmas escolares. 
Nesse mesmo movimento, a Unidade vem mostrando interesse em ofertar formações voltadas à arte e à educação interseccionadas com as lutas sociais. Destacamos o curso "Arte de mulheres e/ou feminista? Intersecções entre gênero, arte e educação" que foi oferecido enfatizando a produção artística de mulheres brasileiras e gaúchas que, por vezes, tem sua história e trabalhos ofuscados ou silenciados na História da Arte. A proposta contou com a pesquisadora Damiana Ballerini, doutora em Estudos de Mulheres e de Gênero pela Universidade de Granada na Espanha. O curso faz parte de ações voltadas à problematização dos contextos socioculturais e a repercussão dos mesmos na educação e nas formas de vida.

Outro exemplo de produção acadêmica-científica que compõem a paisagem existencial da UERGS quanto ao tema das lutas feministas pode ser visto na monografia intitulada "Resistência e Existência LGBTQIA+ a partir de Lampião da Esquina e Chana com Chana (2020)", na qual a autora analisa a construção de modos de viver que deram visibilidade e construíram a resistência dos movimentos por meio dos jornais feministas (CORREA, 2020).

Com a mesma intencionalidade, o PIBID Bagé promoveu uma exposição fotográfica intitulada "Ressonâncias" que circulou pelas duas escolas que eram parceiras do Programa Institucional da Unidade. Dando destaque ao cinema, o Campus da Região da Campanha exibiu filmes com debates ao menos um sábado por mês por mais de dois semestres. As obras cinematográficas discutiram, por exemplo, questões relacionadas à linguagem e à sociedade. $\mathrm{O}$ cinema pedagógico funcionou como possibilidade de ampliação de capital cultural e ganho de conhecimento de arte cinematográfica.

Em outra parceria, os Grupos de Pesquisa DESLOGOGIAS, e PHILOS SOPHIAS, vinculado à Unipampa, realizaram o Curso de Extensão "Infâncias: território de escutas e diálogos”, em 2019, que visou discutir e refletir sobre olhares outros para a infância e Educação Infantil. Em atividades teóricas e práticas, foram realizados encontros quinzenais que abordaram a linguagem na infância, a criança, o brincar, a arte, dentre outras temáticas. Participaram da formação estudantes da UERGS, do Magistério do Município de Bagé e professores atuantes na Educação Infantil. Eles assistiram a filmes, fizeram leituras e tiveram momentos de discussão a fim de reinventar modos de pensar e fazer na educação das infâncias. 
Esta parceria resultou na apresentação de trabalhos em eventos acadêmicos-científicos e publicações, como o artigo "Carta para a Infância: devir criança em devaneios poéticos" (VOSS; CAMOZZATO; MARTINS, 2021).

Nessa cinesia, a Unidade tem fomentado estudos e pesquisas que enfocam na multiplicidade das infâncias, tais como as percebidas e experienciadas através do estágio curricular em anos iniciais vivenciado por uma das discentes da UERGS e que serviu para a escrita do seu trabalho de conclusão do curso de Pedagogia na Unidade Bagé. Como desdobramento, a pesquisa foi apresentada no "Seminário Cosmos: Outros Mundos", organizado pelo Grupo PHILOS SOPHIAS e no Projeto Humanidades Digitais, o que possibilitou a publicação do trabalho intitulado: "Infâncias Pós-modernas: entre capturas e desvios" (FLESCH; VOSS, 2020).

No contexto político atual em que a educação está sob constante ameaça da retórica neoliberal e neoconservadora, pensamos ser primordial assumir princípios de formação éticaestética-política e criar alternativas ao que se apresenta, como tem feito os/as profissionais da UERGS Bagé. O olhar lançado às ações aqui descritas constituem rastros de uma paisagem existencial em construção, um mapa que não se fecha, nem se finda. Cada prática experimentada pelos personagens desta paisagem funciona como um sistema dinâmico que enreda e move forças dentro e fora do seu território, constituindo linhas de (re)existência em defesa da educação pública de qualidade social, desviando-se do descaso e dos constantes ataques de (des)governos do país e do Estado do Rio Grande do Sul.

\section{CONSIDERAÇÕES FINAIS}

Com este trabalho, reafirmamos nosso reconhecimento à UERGS Bagé pela coragem inventiva com que se move em contra-corrente às macropolíticas neoliberais e neoconservadoras. Como dito por Rolnik (2018, p. 65)

E se ampliamos o horizonte do nosso olhar para abranger a superfície do mundo tal como ela se configura na atualidade, constataremos que estamos diante da micropolítica de uma vida, individual ou coletiva, que logra reapropriar-se de sua potência e, com ela, driblar o poder do inconsciente colonial-capitalísitico que a 
expropria. Em suma, uma vida que logra orientar-se por uma ética pulsional. Vida nobre, prolífera vida, vida singular, uma vida.

Em resposta às macropolíticas neoliberais e neoconservadoras, a UERGS forja (re)existências a partir da criação e mobilização de uma rede de aliados em movimentos que traçam a reapropriação da pulsão vital. Afetações que vão na contramão da repetição não criativa de poder-saber-viver encontros com as lutas sociais.

Vislumbramos, assim, a produção da paisagem existencial da UERGS e da Unidade Bagé frente aos constantes ataques à educação universitária pública. Micropolítica de (re)existência que vaza, desterritorializa, produz diferença, afeta e transforma os personagens e os fazeres dessa paisagem, mobilizando sua maquinaria de guerra para combater o fascismo e a perversidade do regime colonial capitalístico contemporâneo. Combate ao estrangulamento da diferença (PELBART, 2019), que se faz em movimentos coletivos de forças da UERGS Campus Bagé, em germinação de possíveis com tantos outros/as.

\section{REFERÊNCIAS}

BRASIL. Lei no 9.394, de 23 de dezembro de 1996. Estabelece as Diretrizes e Bases da Educação Nacional. Diário Oficial da União, Poder Executivo, Brasília, DF, 1996.

BRASIL. Lei no 13.005, de 25 de junho de 2014. Estabelece o Plano Nacional da Educação 2014 -2024. Diário Oficial da União, Poder Executivo, Brasília, 2014.

BOGDAN, Robert C.; BIKLEN, Sari K. Investigação qualitativa em educação: uma introdução à teoria e aos métodos. Portugal: Porto Editora, 1994.

CAMOZZATO, Viviane Castro. Pedagogia, Docência e a Função de Diagnosticar o Tempo Presente. p. 61-86. In: Prática em Docência: Um Projeto em Construção. Universidade Luterana do Brasil - ULBRA. Canoas, 2015.

CORREA, Bruna Soares L. Resistência e Existência LGBTQIA+ a partir de Lampião da Esquina e Chana com Chana (2020), Monografia (Especialização em Gestão de Currículo na Formação Docente) Universidade Estadual do Rio Grande do Sul (UERGS), Unidade Bagé, Bagé (RS), 2020.

DELEUZE, Gilles. Conversações. Tradução de Peter Pául Pelbart. São Paulo: Editora 34, 1992.

DELEUZE, Gilles; GUATTARI, Félix. Mil Platôs: capitalismo e esquizofrenia 2, vol. 01. Tradução de Ana Lúcia de Oliveira, Aurélio Neto e Célia Pinto Costa. $2^{\circ}$ ed. São Paulo: Editora 34, 2011. 
DELEUZE, Gilles; GUATTARI, Félix. Mil Platôs: capitalismo e esquizofrenia 2, vol. 05. Tradução de Peter Pál Pelbart e Janice Caiafa. $2^{\circ}$ ed. São Paulo: Editora 34, 2011.

FLESCH, Jaqueline. Infâncias pós-modernas: os sujeitos infantis da contemporaneidade. SEMINÁRIO ONLINE COSMOS: OUTROS MUNDOS. Grupo de Pesquisa Philos Sophias, Universidade Federal do Pampa, 2020.

FLESCH, Jaqueline; VOSS, Dulce Mari da S. Infâncias Pós-modernas: entre capturas e desvios. In: SANTOS, Amanda B.; MACHADO, Juliana P; COLVERO, Ronaldo B. Anais Humanidades Digitais. Jaguarão: EDICON, 2020, p. 178-191.

FREITAS, Helena C. P. A reforma do ensino superior no campo da formação dos profissionais da educação básica: as políticas educacionais e o movimento dos educadores. Educação e Sociedade, v. 20, n. 68, Campinas, SP, dez. 1999, p. 17-44.

FOUCAULT, Michel. A Ordem do Discurso. Aula Inaugural dada no Collège de France (02/12,1970). $2^{\circ}$ ed. São Paulo: Loyola, 1996, p. 5-70.

FOUCAULT, Michel. Nascimento da Biopolítica. Curso dado no Collège de France (19781979). Tradução de Eduardo Brandão. São Paulo: Martins Fontes, 2008.

FOUCAULT, Michel. Do governo dos vivos. Tradução de Eduardo Brandão. São Paulo: WMF Martins Fontes, 2014.

PELBART, Peter Pául. Ensaios do Assombro. São Paulo: n-1 edições, 2019.

RIO GRANDE DO SUL. Decreto $n^{\circ} 43.240$, de 15 de julho de 2004. Aprova o Estatuto da Universidade Estadual do Rio Grande do Sul - UERGS. Disponível em:

http://www.al.rs.gov.br/legis. Acesso: 01 de março de 2021.

RIO GRANDE DO SUL. Lei no 11.646, de 10 de julho de 2001. Autoriza o Poder Executivo a criar a Universidade Estadual do Rio Grande do Sul - UERGS e dá outras providências. Atualizada até a Lei 14.631, de 15 de dezembro de 2014. Disponível em:

http://www.al.rs.gov.br/legis. Acesso: 01 de março de 2021.

ROLNIK, Suely. Esferas da Insurreição: notas para uma vida não cafetinada. São Paulo: n-1 edições, 2018.

TEDESCHI, Sirley Lizott; PAVAN, Ruth. A produção do conhecimento em educação: o Pósestruturalismo como potência epistemológica. Práxis Educativa, Ponta Grossa, Ahead of Print, v. 12, n. 3, set./dez. 2017.

UNIVERSIDADE ESTADUAL DO RIO GRANDE DO SUL. Institucional: Sobre a UERGS. Disponível em: https://www.uergs.edu.br/sobre-a-uergs. Acesso: 02 de março de 2021.

UNIVERSIDADE ESTADUAL DO RIO GRANDE DO SUL. Unidades Universitárias: Bagé. Disponível em: https://www.uergs.edu.br/bage. Acesso: 02 de março de 2021.

VOSS, Dulce Mari da S. Habitar outros mundos em tempos sombrios. In: ROCHA, Paulo Henrique B.; MAGALHÃES, José Luiz Q.; OLIVEIRA, Patrícia M. P. Decolonialidade a partir do Brasil, vol 01. Belo Horizonte: Editora Dialética, 2020, p. 221-239. 
VOSS, Dulce Mari da S. Trabalho e saúde docente no jogo biopolítico das reformas educacionais. Revista Educação e Cultura Contemporânea, vol. 18, n. 52, 2021.

VOSS, Dulce Mari da S.; CAMOZZATO, Viviane; MARTINS, Semíramis C. Carta para Infância: devir criança em devaneios poéticos. Revista Artes de Educar, vol. 07, n. 01, 2021.

Submetido: 07/03/2021

Aprovado: 05/04/2021 